\title{
Steel Hull Corrosion of USS Arizona with Applications to Submerged Resources
}

\author{
D.L. Johnson, ${ }^{*}$ D.J. Medlin, ${ }^{* *}$ M.A. Russell, ${ }^{* * *}$ D.L. Conlin, ${ }^{* * *}$ L.E. Murphy, ${ }^{* * *}$ J.D. Carr ${ }^{* * * *}$ \\ * Dept. of Mechanical Engineering, University of Nebraska-Lincoln, Lincoln, NE 68588 \\ ** Department of Materials and Metallurgical Engineering, South Dakota School of Mines \& \\ Technology, Rapid City, South Dakota 57701 \\ *** National Park Service Submerged Resources Center, P.O. Box 728, Santa Fe, NM 87505 \\ **** Department of Chemistry, $624 \mathrm{HaH}$, University of Nebraska-Lincoln, Lincoln, NE 68588
}

The USS Arizona Preservation project is a multi-year, interdisciplinary and cumulative effort with each discipline contributing to basic research required to make informed management decisions for long-term preservation. Three significant issues include: (1) USS Arizona is a grave site for 900 or more Navy and Marine personal lost with the USS Arizona when Japanese forces attacked Pearl Harbor on Dec 7, 1941. (2) Minimizing environmental hazard from a potential fuel oil release of an estimated 500,000 gallons remaining in fuel bunkers or compartment overheads. A cross section view of the ship and bunkers before and after the attack is shown in Fig. 1. (3) Over 1.5 million visitors a year consider the vessel a national icon. Research and any solution to the oil issue incorporates a minimum impact approach. The primary goal of the project is to characterize complex deterioration processes and utilize finite element modeling (FEM) to predict stability in the context of a variety of interdisciplinary inputs including geology, oceanography, microbiology, oil analysis, structures, environmental parameters and corrosion. In addition to informing management, the research has produced results applicable to thousands of submerged steel vessels worldwide. The following is a discussion of corrosion research on USS Arizona and application of the Concretion Equivalent Corrosion Rate (CECR) methodology.

Corrosion research on Arizona began with metallurgical studies of Arizona superstructure samples and was the beginning of a continuing partnership between the University of Nebraska- Lincoln and the Submerged Resources Center (SRC), National park Service. Results were presented at IMS in 1999 [1]. As reported, banding was observed, as shown in Fig. 2, but was assumed to have no effect on corrosion. Recently, a study of microstructural and rivet/plate galvanic effects was initiated along with metallurgical analysis of plate removed from the hull in 2002.

Eight $10 \mathrm{~cm}$ (4 in) diameter hull samples (coupons) were removed, four each from port and starboard sides near midship, at vertical positions from $5 \mathrm{ft}(1.5 \mathrm{~m})$ to just below the mudline at $34 \mathrm{ft}$ $(10.4 \mathrm{~m})$. Corrosion rate was determined by subtracting final thickness from original thickness and dividing the difference by the submerged time interval, 61 years. Fig. 3 is a port side bar graph of hull plate thickness as a function of water depth [2]. At $5 \mathrm{ft}(1.5 \mathrm{~m})$, the metal loss is over $50 \%$ of original thickness due to fresh seawater exposure on both sides. At $19.5 \mathrm{ft}(6 \mathrm{~m})$, the loss is less than $25 \%$, at $26 \mathrm{ft}(8 \mathrm{~m})$ and lower, the loss is less than $15 \%$. Corrosion rate varies from $2.7 \mathrm{mpy}$ ( $0.07 \mathrm{mmpy})$ near the surface to $1.2 \mathrm{mpy}(0.031 \mathrm{mmpy})$ at the mudline. USS Arizona's complete structural deterioration and eventual release of oil inside the hull is, by all indications, not imminent.

Since acquisition of metal coupon sampling is expensive and invasive, data from the eight coupons became baseline for studying minimum impact techniques such as corrosion potential [3], ultrasonic thickness and concretion analysis. Iron accumulation as siderite ( $\mathrm{FeCO} 3)$ in naturally forming 
concretion (biofouling) was first reported by North on wrought and cast iron shipwrecks [3][4]. XRD (x-ray diffraction) and ESEM (environmental scanning electron microscopy) studies revealed similar findings on Arizona concretion. Based on these results, CECR was developed as a minimum-impact technique to estimate corrosion rate of metal from density, thickness and iron content of the concretion [2]. As an example application, CECR predicts a corrosion rate of 0.6 mpy ( $11 \%$ of original hull thickness) for Japanese Midget submarine I-20A submerged in $1300 \mathrm{ft}(400 \mathrm{~m})$ of water, three miles south of Pearl Harbor [5]. An extension of CECR, referred to as $\operatorname{Jn}(\mathrm{I}) \mathrm{Index}$, is now under study to predict corrosion rate as a function of temperature, oxygen concentration, salinity and concretion thickness.

References

[1] D.L. Johnson et al, Proceedings, IMS (1999).

[2] M.A. Russell et al, Int. J. Naut. Arch., 35.2 (2006).

[3] I.D. MaCleod, Int. Hbk of Underwater Arch., Plenum (2002).

[4] N.A. North, Int J. Nautical Arch. and Underwater Exploration, 5.3 (1976).

[5] B.M. Wilson et al, J. of Metals (2006).

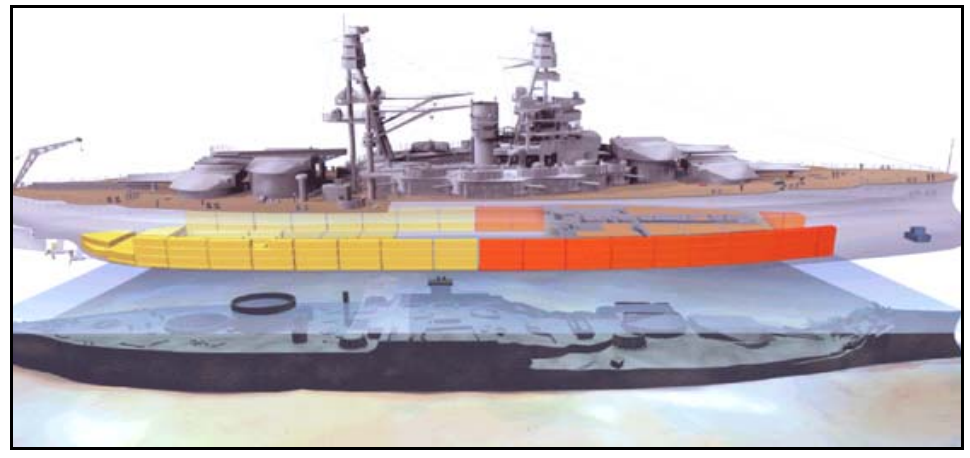

Fig.1. USS Arizona - Destroyed bunkers in red; intact in yellow (courtesy of National Geographic and NPS).

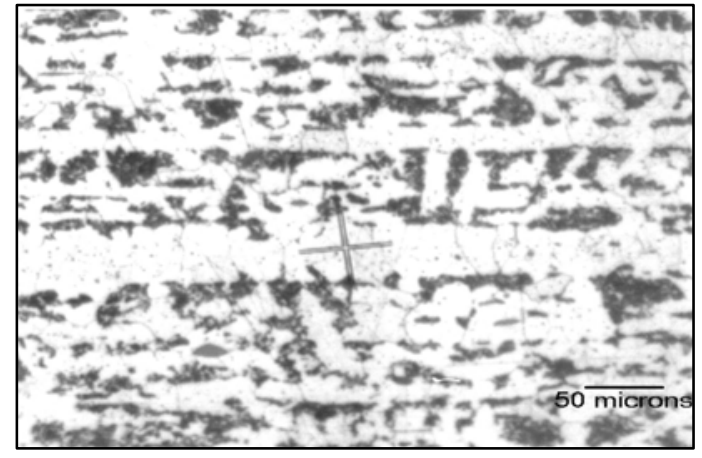

Fig. 2. Alignment of ferrite and pearlite in bands, $0.1 \mathrm{C}$, boat deck plate, (1913).

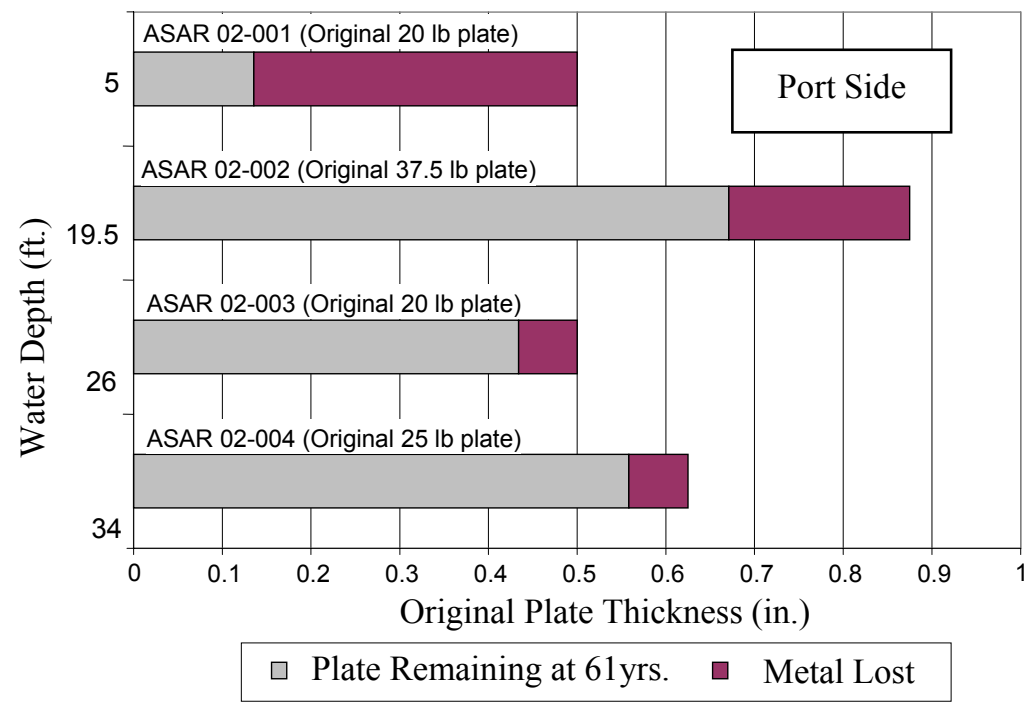

Fig 3. Plate loss as a function of water depth. 